\title{
COMMENTARY
}

\section{Managing blood glucose in critically ill patients with or without diabetes}

\author{
Simon Finfer ${ }^{* 1,2}$ and Laurent Billot ${ }^{1}$ \\ See related research by Krinsley et al., http://ccforum.com/content/17/2/R37
}

\begin{abstract}
Relationships between blood glucose concentration and outcome and also the optimum management of blood glucose remain highly contentious issues for critical care practitioners. Among the many controversies is whether critically ill patients with diabetes should be treated differently from those without diabetes. Krinsley and colleagues assembled a large observational database that sheds further light on the relationships of hyperglycemia, hypoglycemia and glucose variability and risk of death in critically ill patients with and without diabetes. Defining the optimum treatment and whether this should differ by diabetic status requires high-quality primary interventional research.
\end{abstract}

The best management of stress-induced hyperglycemia in critically ill patients remains unknown and among the many controversies is whether patients with diabetes should be managed differently from those without diabetes. In a recent edition of Critical Care, Krinsley and colleagues report on associations between the three domains of glycemic control' (hyperglycemia, hypoglycemia and glucose variability) in patients with or without a diagnosis of diabetes [1]. They assembled and analyzed a large database containing data from patients admitted to $23 \mathrm{ICUs}$ in nine countries. Their purpose was to determine how diabetic status affected the relationships between glycemic control and outcome.

Krinsley and colleagues report some interesting findings. For critically ill patients in general, the relationship between mean blood glucose concentration [BG] and outcome is known to be U-shaped, with increased

${ }^{*}$ Correspondence: sfinfer@georgeinstitute.org.au

IIntensive Therapy Unit, Level 6, Acute Services Building, Royal North Shore

Hospital, Pacific Highway, St. Leonards, NSW 2065, Australia

Full list of author information is available at the end of the article mortality observed with both high and low mean [BG] [2]. When examining those patients with and without diabetes separately, Krinsley and colleagues report that the nadir of the U-shaped curve (the [BG] associated with lowest mortality) occurs at a different [BG] in those with diabetes. In patients with diabetes, an associated increase in mortality does not occur until a higher [BG]. Moderate and severe hypoglycemia (defined as minimum [BG] 40 to $69 \mathrm{mg} / \mathrm{dl}(2.2$ to $3.8 \mathrm{mmol} / \mathrm{l})$ and $<40 \mathrm{mg} / \mathrm{dl}$ $(<2.2 \mathrm{mmol} / \mathrm{l})$, respectively) were associated with increased mortality regardless of diabetic status, whereas increased $[\mathrm{BG}]$ variability defined by the coefficient of variation was only associated with increased risk of death in patients without diabetes.

How should we interpret these findings? Do they contradict or support what we already know about patients with diabetes admitted to ICUs, and should these results influence how we treat patients with diabetes?

Firstly, we should recognize both the strengths and the weaknesses of the study. The strength of the study is mainly its size and that the authors drew data from different ICUs in different countries. The weaknesses are the observational nature of the study, which limits the inferences that can be drawn, and the lack of data on the actual management of [BG]. Additionally, the authors did not have access to measures of glycemic control prior to admission to the ICU and so their presumption that patients with diabetes may behave differently due to adaptive mechanisms developed owing to chronic hyperglycemia is based on supposition rather than on objective measurements such as glycosylated hemoglobin.

What do we already know about patients with diabetes treated in ICUs? Patients with known diabetes have typically constituted around 15 to $20 \%$ of patients enrolled in trials of intensive versus conventional glucose control in the ICU [3,4], and perhaps around 19\% of patients admitted to ICUs overall [5]. With the notable exception of patients undergoing cardiac surgery, a diagnosis of diabetes is not associated with an increased risk of death following admission to the ICU [5]. The reasons for this somewhat surprising finding have been 
discussed, including that patients with diabetes may be receiving medications that increase their chances of surviving critical illness [6]. An alternative explanation is that the apparent protective effect of diabetes is due to other confounding influences - for example, less sick patients with diabetes being admitted to the ICU because they are incorrectly perceived to be at increased risk of death. Data from randomized trials also confirm that patients with diabetes do not benefit from being treated with insulin with the goal of achieving normoglycemia $[3,4]$, although whether they differ from patients without diabetes in this regard remains unclear and cannot be determined using observational data.

While researchers have studied the effects of different blood glucose targets on the long-term outcomes of ambulant patients with diabetes [7], there has been no study specifically examining the effects of different blood glucose targets in critically ill patients with diabetes. As the optimum [BG] target for critically ill patients overall is not known, it would be vastly premature to call for future studies to be limited to patients with diabetes. This question can be addressed in an appropriately designed study recruiting ICU all-comers as long as patients with type I and type II diabetes are identified at baseline. Stratifying randomization by a diagnosis of diabetes would further increase the robustness of the results.

In conclusion, Krinsley and colleagues report that the associations between [BG] and outcome are different in patients with and without diabetes although appropriate targets for management of blood glucose concentration can only be defined by future randomized trials. Such trials can and should be designed to determine whether treatment effects differ in patients who do or do not have diabetes at the time of enrolment.
Abbreviations

[BG], blood glucose concentration.

\section{Competing interests}

The authors declare that they have no competing interests.

\section{Author details}

'The George Institute for Global Health, University of Sydney, PO Box M201, Missenden Road, Sydney, NSW 2050, Australia. ${ }^{2}$ Intensive Therapy Unit, Level 6, Acute Services Building, Royal North Shore Hospital, Pacific Highway, St. Leonards, NSW 2065, Australia.

Published: 18 April 2013

\section{References}

1. Krinsley JS, Egi M, Kiss A, Amin DN, Schuetz P, Maurer PM, Schultz MJ, van Hooijdonk RT, Kiyoshi M, Mackenzie IM, Annane D, Stow P, Nasraway SA, Holewinski S, Holzinger U, Preiser JC, Vincent JL, Bellomo R: Diabetic status and the relationship of the three domains of glycemic control to mortality in critically ill patients: an international multicenter cohort study. Crit Care 2013, 17:R37.

2. Siegelaar SE, Hermanides J, Oudemans-van Straaten HM, van der Voort PH, Bosman RJ, Zandstra DF, DeVries JH: Mean glucose during ICU admission is related to mortality by a U-shaped curve in surgical and medical patients: a retrospective cohort study. Crit Care 2010, 14:R224.

3. Van den Berghe G, Wilmer A, Milants I, Wouters PJ, Bouckaert B, Bruyninckx F, Bouillon $\mathrm{R}$, Schetz M: Intensive insulin therapy in mixed medical/surgical intensive care units: benefit versus harm. Diabetes 2006, 55:3151-3159.

4. NICE-SUGAR Study Investigators: Intensive versus conventional glucose control in critically ill patients. N Engl J Med 2009, 360:1346-1349.

5. Siegelaar SE, Hickmann M, Hoekstra JB, Holleman F, Devries JH: The effect of diabetes on mortality in critically ill patients: a systematic review and meta-analysis. Crit Care 2011, 15:R205.

6. Finney SJ: The good and the bad of diabetes mellitus in the critically ill. Crit Care 2011, 15:1018.

7. The ADVANCE Collaborative Group: Intensive blood glucose control and vascular outcomes in patients with type 2 diabetes. N Engl J Med 2008, 358:2560-2572.

doi:10.1186/cc12591

Cite this article as: Finfer S, Billot L: Managing blood glucose in critically ill patients with or without diabetes. Critical Care 2013, 17:134. 